\title{
sciendo
}

\section{Radiological characterization of the phosphate deposit in Al-Jalamid phosphate mining area, Saudi Arabia}

\author{
Abdulsalam M. Alhawsawi $\mathbb{0}$, \\ E. I. Shababa, \\ Maher M. T. Qutub, \\ Essam M. Banoqitah (D,
}

A. A. Kinsara

\begin{abstract}
It is a known fact that phosphate rocks have high levels of natural radioactivity due to the presence of large concentrations of radionuclides. This work aims to estimate radiation exposure and dose levels at Al-Jalamid site in northern Saudi Arabia. Al-Jalamid area is one of the largest reserves of phosphate worldwide. Ma'aden, a Saudi Government public company, owns the mine and is responsible for all mining activities. Phosphate and soil samples collected from Al-Jalamid phosphate mining area have been analysed for their uranium and thorium content by an $\alpha$-spectrometer using radiochemical techniques. The quantity of radon gas was measured both in groundwater and in the atmosphere (indoor and outdoor) at the site using a portable radiation survey instrument. Groundwater samples collected from wells surrounding the mining area were analysed using a liquid scintillation counter in addition to an $\alpha$-spectrometer. Finally, it is found that phosphate rock concentrate products cannot be utilized economically based on the standards set by the International Atomic Energy Agency (IAEA), since the average activity concentration does not reach the limit set by IAEA and hence are not commercially feasible.
\end{abstract}

Keywords: Al-Jalamid site $\bullet$ Uranium and thorium in phosphate rocks $\bullet$ Phosphate deposits $\bullet$ Natural radioactivity • Environmental radioactivity and pollution • Groundwater

\author{
A. M. Alhawsawi ${ }^{凶}$, M. M. T. Qutub \\ Center for Training \& Radiation Prevention \\ King Abdulaziz University \\ P. O. Box 80204, Jeddah 21589, Saudi Arabia \\ and Department of Nuclear Engineering \\ Faculty of Engineering, King Abdulaziz University \\ P. O. Box 80204, Jeddah 21589, Saudi Arabia \\ E-mail: amalhawsawi@kau.edu.sa \\ E. I. Shababa \\ Center for Training \& Radiation Prevention \\ King Abdulaziz University \\ P. O. Box 80204, Jeddah 21589, Saudi Arabia \\ E. M. Banoqitah, A. A. Kinsara \\ Department of Nuclear Engineering \\ Faculty of Engineering \\ King Abdulaziz University \\ P. O. Box 80204, Jeddah 21589, Saudi Arabia
}

Received: 29 June 2020

Accepted: 2 October 2020

\section{Introduction}

The old Tethys Ocean, also known as the Tethys Sea, is the place from where the Mediterranean Sea originated and it separates Europe and Asia from Africa. The Tethys Sea flew across the Middle East and North Africa, an area that begins in northwest Saudi Arabia and extends across south Jordan, Egypt, Tunisia, Algeria and Morocco [1]. This area possesses the largest phosphate deposits worldwide. These deposits are composed of organic remains of plants and animals that decayed into a sedimentary series around 60-70 million years ago, which resulted in the formation of current dolomites, limestones, and shales. Further, organic ooze of this ocean became phosphorous deposits because of the process of diagenesis. Florida phosphate deposits are also found along a stretch on the southern Mediterranean. At the far eastern end of the Florida, phosphate deposit line is located in northern Saudi Arabia, which is one of the world's largest reserves of phosphate ore [1].

It is well known that phosphate minerals usually contain naturally occurring radionuclides whose activity is enhanced by geological processes, as uranium replace calcium in the rock formation. However, several studies [2-9] have been conducted worldwide to study natural radioactivity of the phosphate deposits, and its radiological impact

0029-5922 @ 2021 The Author(s). Published by the Institute of Nuclear Chemistry and Technology.

This is an open access article under the CC BY-NC-ND 4.0 licence (http://creativecommons.org/licences/by-nc-nd/4.0/). 
on the workers and the surrounding environment due to mining, processing, packing, and other mining related activities. All these studies have indicated that sedimentary phosphate rocks of different origin contain high ${ }^{238} \mathrm{U}$ activity concentrations ranging between $150 \mathrm{~Bq} / \mathrm{kg}$ and $4800 \mathrm{~Bq} / \mathrm{kg}$, and much lower ${ }^{232} \mathrm{Th}$ activity concentrations ranging between $16 \mathrm{~Bq} / \mathrm{kg}$ and $78 \mathrm{~Bq} / \mathrm{kg}[6,10,11]$. Other studies have reported that concentration values for uranium are lower than $150 \mathrm{~Bq} / \mathrm{kg}$ [12-14]. The main source of radiation in sedimentary phosphate rocks is the uranium series radionuclides. Most of these studies are consistent in reporting that the ratio of ${ }^{238} \mathrm{U}$ to ${ }^{226} \mathrm{Ra}$ activity concentration is almost equivalent to unity, showing radioactive equilibrium among radionuclides of the uranium decay series. Moreover, thorium concentration in phosphate rocks of igneous origin is often equal to the concentration uranium, although both are present in smaller quantities [5]. In his work, [5] reported typical concentration values for ${ }^{238} \mathrm{U}$ to ${ }^{232} \mathrm{Th}$ which are as follows: (a) 638 $\pm 153 \mathrm{~Bq} / \mathrm{kg}$ to $258 \pm 18 \mathrm{~Bq} / \mathrm{kg}$, (b) $298 \pm 148$ $\mathrm{Bq} / \mathrm{kg}$ to $284 \pm 20 \mathrm{~Bq} / \mathrm{kg}$, and (c) $344 \pm 94 \mathrm{~Bq} /$ $\mathrm{kg}$ to $246 \pm 17 \mathrm{~Bq} / \mathrm{kg}$ in some Brazilian phosphate rocks of igneous origin. Generally, the levels of ${ }^{40} \mathrm{~K}$ and ${ }^{232} \mathrm{Th}$ in all phosphates are similar to that in natural soil [15]. Furthermore, the International Atomic Energy Agency (IAEA) reported that natural uranium concentrations greater than 200 parts per million (ppm), which is equivalent to about $2460 \mathrm{~Bq} / \mathrm{kg}$, are of potential interest as uranium can be obtained as a byproduct economically rather than shipping it as a contaminant in the phosphate fertilizer [16]. This can be achieved by installing solvent extraction circuits in the fertilizer manufacturing facility [17].

Several investigations have been conducted to assess natural radioactivity in the phosphate deposits of the Tethys Sea $[4,18,19]$. Only one study is pertained to natural radioactivity in the phosphate deposits in northwestern Saudi Arabia [20]. The investigations now focus its attention on studying and characterizing natural radioactivity in the phosphate ore of Al-Jalamid phosphate mines located in northern Saudi Arabia. Data presented in those research efforts reveal a knowledge gap that requires additional investigation to further characterize the radiological levels in phosphate deposits at the Tethys Sea in northern Saudi Arabia. Additionally, results of this work will be compared to several phosphate deposit data worldwide. Therefore, the main objectives of this work can be summarized as: (a) characterizing natural radioactivity in phosphate deposits of Al-Jalamid phosphate mining area. Mining and processing activities started in 2010 in this mine, which is considered the first site when Ma'aden started the processing of phosphate; (b) characterizing the raw mineral phosphate ore, the beneficiated ore, reject, soil, and mining waste in terms of radioactivity levels; and (c) finally exploring whether the average uranium concentration in the beneficiated phosphate ore that is used as a feed for fertilizer production can be recovered economically as a byproduct from the local mining industry.

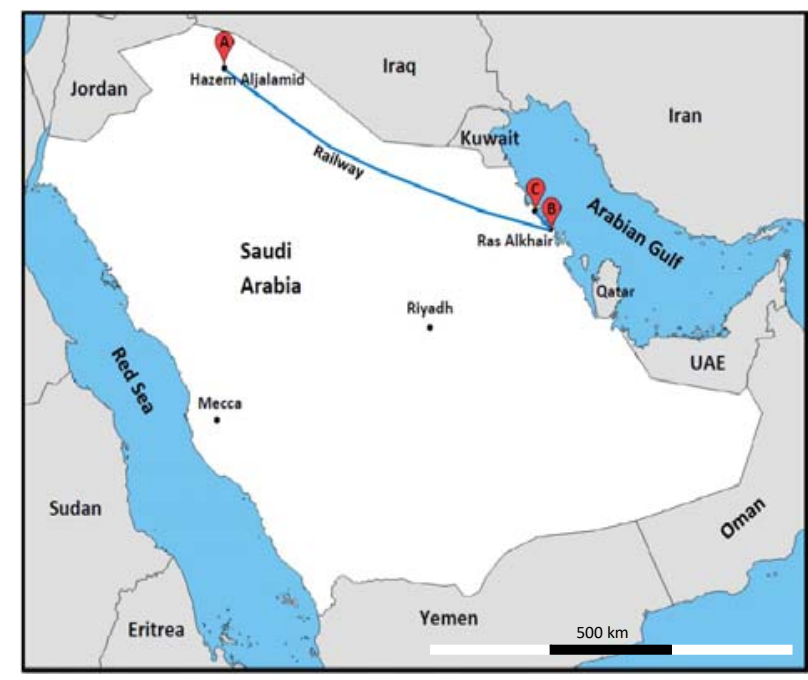

Fig. 1. A map of Saudi Arabia showing the location of the mining site $(\mathrm{A})$, the processing complex $(\mathrm{B})$, and the fertilizer exportation marine port (C).

\section{Materials and methods}

\section{Location and nature of the mining area}

Al-Jalamid phosphate mining area lies in Hazm Al-Jalamid Quadrangle (long. $39^{\circ} 00^{\prime}$ and $40^{\circ} 30^{\prime} \mathrm{E}$ and lat. $31^{\circ} 00^{\prime}$ and $32^{\circ} 00^{\prime} \mathrm{N}$ ), northwest of Saudi Arabia (see Fig. 1).

Location A comprises of two adjacent phosphate mines, physical beneficiation site and chemical beneficiation plant [21]. The phosphate concentrate is transported by rail and trucks from Al-Jalamid to the phosphate processing complex in Ras $\mathrm{Al}$ Khair, situated at the western coast of the Arabian Gulf at location B, shown also in Fig. 1, to manufacture phosphate fertilizers for exporting from the marine port in location C, shown in Fig. 1. Hazm Al-Jalamid Quadrangle contains early tertiary sedimentary rocks of Turayf Group along with other sedimentary deposits [22]. The sedimentary rocks exposed at the surface include Al-Jalamid, Mira, and Umm Wa'al formation of the Turayf Group. Al-Jalamid formation was deposited in a shallow marine environment. It is found mostly as pelletal phosphorite, dolomitic limestone, limestone, in addition to argillaceous, silicified limestone, and some dolostone. All the three formations of the Turayf Group (Urn Wu'al, Mira and Al-Jalamid formations) have the potential for commercial development. Other deposits in the surrounding area that might be suitable for commercial development include the Thaniyat, Turayf, and As Sanam deposits [22].

\section{Sampling}

On-site observation of the mines showed that the exposed phosphate deposits exist in two layers namely upper and lower layers. The upper deposit layer is $5-8 \mathrm{~m}$ thick and the lower deposit layer is $1-3 \mathrm{~m}$ thick. The two layers are separated by a $0.1 \mathrm{~m}$ to $2 \mathrm{~m}$ thick waste deposit. The upper phos- 
phate layer is topped up by an overburden layer; consist of mining waste mixed with soil that is around $18 \mathrm{~m}$ in thickness.

According to the documents of Ma'aden mining company, the raw ore contains $20-25 \%$ of $\mathrm{P}_{2} \mathrm{O}_{5}$ and $51-54 \%$ of $\mathrm{CaO}$. On-site beneficiation activities, either by physical (sizing) or chemical (floatation) processes, increased $\mathrm{P}_{2} \mathrm{O}_{5}$ concentration to about $30 \%$. Also, the radioactivity in phosphate rocks may vary from one location to another based on ground samples. Because of this reason, numerous samples representing the varieties of rocks and soils from all locations were collected to increase the probability of finding any radiometric anomalies that may exist.

Raw phosphate samples were collected from the upper and lower phosphate layers. Other samples were collected from the beneficiated ore (concentrate) and reject piles inside the beneficiation plant before transporting to the processing complex in Ras $\mathrm{Al}$ Khair. In the open mines, ground samples from the overburden layer composed of mining waste mixed with soil, and the lower waste layer were also used for samples. In all samples, large gravels, stones and other objects were removed by a $2 \mathrm{~mm}$ sieve and about 1 liter of the soil was labelled and packed in plastic bags.

Topsoil samples known as natural soil were collected from several undisturbed and non-mining sites. Topsoil samples were collected from an area of more than $0.25 \mathrm{~m}^{2}$ and from a depth of $5 \mathrm{~cm}$ into the ground.

All samples were labelled, sealed, and transferred to the laboratory for measurements and analysis. Then, the samples are prepared for the radio analytical procedure: they were dried at room temperature for several days, ground, and mixed. An aliquot of the mixed sample was heated in a muffle furnace at $550^{\circ} \mathrm{C}$ for about 20 hours to get rid of organic remains and eliminate carbonates. The resulting sample weight was corrected against the field sample weight. The samples were analysed for their uranium and thorium content by an $\alpha$-spectrometer using radiochemical techniques. The detailed radiochemical technique is described in Appendix A.

\section{Measurement of uranium and thorium isotopes}

Uranium was separated from other sample components by ion exchange technique and co-precipitated with $\mathrm{Nd}^{3+}$ as fluoride on a membrane filter for measurement [23]. About $0.5 \mathrm{~g}$ of each sample was digested in a $400-\mathrm{mL}$ Teflon beaker for complete dissolution using concentrated $\mathrm{HNO}_{3} / \mathrm{HCl}$. For samples containing silica, HF was used apart from the concentrated $\mathrm{HNO}_{3} / \mathrm{HCl}$ acids to attain complete dissolution. The sample was evaporated to dryness and about $3 \mathrm{~mL}$ of concentrated $\mathrm{HCl}$ was added and fully evaporated to convert the medium to the $\mathrm{Cl}^{-}$form. The final step was repeated twice to complete the conversion process.

The sample residue was taken up in $20 \mathrm{~mL}$ of $10 \mathrm{M} \mathrm{HCl}$ solution and loaded into $10 \mathrm{~mL}$ separation column (from Bio Rad) packed with AG 1-X8 anion exchanger ( $5 \mathrm{~mL}$ bed volume). The column was preconditioned by passing $20 \mathrm{~mL}$ of $10 \mathrm{M} \mathrm{HCl}$. The trapped uranium was washed with another $20 \mathrm{~mL}$ of $10 \mathrm{M} \mathrm{HCl}$ and eluted from the column by passing $20 \mathrm{~mL}$ of $0.1 \mathrm{M} \mathrm{HCl}$.

Then, for further preparation of the uranium source, $50 \mu \mathrm{L}$ of $\mathrm{Nd}^{3+}$ solution $\left(1 \mathrm{mg} \mathrm{Nd} d^{3+} / \mathrm{mL}\right.$, as chloride) was added to the separated uranium (the eluate) followed by an amount of $\mathrm{TiCl}_{3}(15 \%)$ drop-by-drop to change the solution colour to purple, and then an additional $1 \mathrm{~mL}$ was added to keep uranium in the tetravalent state. Five $\mathrm{mL}$ of $40 \%$ HF solution was added to the sample for uranium precipitation as fluoride and was left for $30 \mathrm{~min}$ prior to filtration using $0.1 \mu \mathrm{m}$ polypropylene membrane filter. The precipitate was washed with $3 \mathrm{~mL}$ of $4 \%$ $\mathrm{HF}$, then with $3 \mathrm{~mL}$ of $80 \%$ ethanol solution. The sample was dried at $50^{\circ} \mathrm{C}$ for $5 \mathrm{~min}$, placing and fixing it on a stainless-steel disc using an adhesive tape, and counted.

Thorium was separated exactly as uranium except that the sample was spiked with ${ }^{229}$ Th radiotracer (instead of ${ }^{232} \mathrm{U}$ ), and 8 molar (M) and $1 \mathrm{M}$ of $\mathrm{HNO}_{3}$ solutions were used in loading and eluting thorium instead of $10 \mathrm{M}$ and $0.1 \mathrm{M}$ of $\mathrm{HCl}$ solutions in case of uranium, respectively. Thorium source was also prepared similar to uranium except the addition of $\mathrm{TiCl}_{3}$ solution because thorium is permanently in the tetravalent state [23].

\section{Quality control}

For quality control and validating the obtained radiological data, the analytical procedures of simultaneous determination of uranium isotopes and thorium isotopes in the environmental samples were tested against standard reference materials supplied by the IAEA. These references are RGU-1 and RGTh-1, which were prepared by dilution of uranium ore and thorium ore, respectively, with floated silica powder [24]. The radionuclides of uranium and thorium series are in radioactive equilibrium in these reference materials. Repetitive determinations of ${ }^{238} \mathrm{U},{ }^{234} \mathrm{U}$, ${ }^{230} \mathrm{Th}$, from uranium series, and ${ }^{232} \mathrm{Th}$ and ${ }^{228} \mathrm{Th}$ from the thorium series were performed and the obtained results are presented in Table 1.

The obtained results in Table 1 for the repetitive determination of uranium isotopes in RGU-1 reference materials show that the precision in this activity level $4940 \pm 30 \mathrm{~Bq} / \mathrm{kg}$, lies between $7.1 \%$ and $9 \%$. Higher precision percentages imply an imprecise result. At uranium activity levels of $78 \pm 6 \mathrm{~Bq} / \mathrm{kg}$ in the RGTh-1 reference material, the obtained results lie between $10.1 \%$ and $11.9 \%$, which is also an imprecise compared to the RGU-1 reference material due to the small sample size and low count rate.

Results from repetitive determination of thorium isotopes in the RGU-1 reference material show that the precision in the level of $4940 \pm 30 \mathrm{~Bq} / \mathrm{kg}$ for ${ }^{230} \mathrm{Th}$ (a member of the U-series) lies between 7.5\% and $7.7 \%$. At activity concentrations of $3250 \pm 90$ $\mathrm{Bq} / \mathrm{kg}$ of the other thorium isotopes $\left({ }^{232} \mathrm{Th}\right.$ and ${ }^{228} \mathrm{Th}$ ) in the RGTh-1 reference, precision ranges between 
Table 1. Results of analysing uranium and thorium isotopes in IAEA reference materials (RGU-1 and RGTh-1)

\begin{tabular}{|c|c|c|c|c|c|c|c|}
\hline \multirow{2}{*}{ Sample } & \multicolumn{3}{|c|}{ Measured values } & \multirow{2}{*}{$\begin{array}{l}\text { Reference } \\
\text { value }\end{array}$} & \multicolumn{2}{|c|}{ Measured values } & \multirow{2}{*}{$\begin{array}{l}\text { Reference } \\
\text { value }\end{array}$} \\
\hline & ${ }^{238} \mathrm{U}$ & ${ }^{234} \mathrm{U}$ & ${ }^{230} \mathrm{Th}$ & & ${ }^{232} \mathrm{Th}$ & ${ }^{228} \mathrm{Th}$ & \\
\hline \multirow[t]{4}{*}{$\overline{\text { RGU-1 }}$} & $4649 \pm 418$ & $4893 \pm 427$ & $5004 \pm 374$ & $4940 \pm 30$ & $5 \pm 2$ & $6 \pm 2$ & $<4$ \\
\hline & $4557 \pm 338$ & $4777 \pm 365$ & $4811 \pm 365$ & & $7 \pm 3$ & $6 \pm 2$ & \\
\hline & $4797 \pm 425$ & $4723 \pm 402$ & $4886 \pm 378$ & & $4 \pm 3$ & $5 \pm 2$ & \\
\hline & $5288 \pm 376$ & $5489 \pm 431$ & $4768 \pm 361$ & & $6 \pm 2$ & $5 \pm 2$ & \\
\hline Average & $4823 \pm 39$ & $4970 \pm 40$ & $4867 \pm 38$ & & $6 \pm 3$ & $6 \pm 3$ & \\
\hline $\mathrm{CV}^{*}$ & 0.81 & 0.82 & 0.78 & & 50 & 50 & \\
\hline \multirow[t]{4}{*}{ RGTh-1 } & $75 \pm 11$ & $71 \pm 11$ & $70 \pm 8$ & $78 \pm 6$ & $3319 \pm 206$ & $3453 \pm 214$ & $3250 \pm 90$ \\
\hline & $88 \pm 10$ & $89 \pm 9$ & $73 \pm 9$ & & $2987 \pm 214$ & $3173 \pm 226$ & \\
\hline & $83 \pm 9$ & $84 \pm 10$ & $75 \pm 8$ & & $3358 \pm 231$ & $2794 \pm 205$ & \\
\hline & $79 \pm 9$ & $78 \pm 9$ & $69 \pm 8$ & & $3335 \pm 184$ & $3252 \pm 181$ & \\
\hline Average & $81 \pm 6$ & $81 \pm 6$ & $72 \pm 6$ & & $3250 \pm 29$ & $3168 \pm 29$ & \\
\hline $\mathrm{CV}^{*}$ & 7.41 & 7.41 & 8.33 & & 0.89 & 0.92 & \\
\hline
\end{tabular}

$* \mathrm{CV}=$ coefficient of variation $=($ standard deviation/average value $) \times 100$.

$5.5 \%$ and $7.3 \%$. At activity levels of thorium isotopes $<4 \mathrm{~Bq} / \mathrm{kg}$ in RGU-1, the obtained results are significantly less precise as shown in Table 1 due to the small sample size and the low count rate.

The accuracy, which is a deviation from the mean value of the confidence range in determination of uranium isotopes in the RGU-1 reference ranges from $7.7 \%$ to $11.1 \%$. This is equivalent to an activity level of $4940 \pm 30 \mathrm{~Bq} / \mathrm{kg}$. On the other hand, the activity level of $78 \pm 6 \mathrm{~Bq} / \mathrm{kg}$ in the RGTh-1 has an accuracy value ranging from $9 \%$ to $14 \%$. Despite the very low background level of the counting system, the determination of thorium isotopes of activity concentrations $<4 \mathrm{~Bq} / \mathrm{kg}$ was significantly less accurate due to the very small sample size and the sample low count rate.

The collected data is quite sufficient for analysing phosphate samples of activity concentrations between $300 \mathrm{~Bq} / \mathrm{kg}$ and $600 \mathrm{~Bq} / \mathrm{kg}$ of uranium series radionuclides, despite the small sample size $0.5 \mathrm{~g}$. High activity concentration, long counting time, and the low detection limit of the counting system are the reasons for this level of accuracy and precision.

\section{Equipment}

ORTEC ensemble was also used to measure the activity of uranium and thorium isotopes in addition to a high-resolution $\alpha$-spectrometry system. The $\alpha$-spectrometry system consists of eight independently operated, $450 \mathrm{~mm}^{2}$ silicon surface barrier detectors located in separate chambers connected to a vacuum pump. The efficiency of the detectors ranges from $20 \%$ to $21.5 \%$. The background count rate was about 1 count/18 hours under each of the used energy peaks resulting in a minimum detection limit of 4 counts/ 18 hours, which is equivalent to $0.56 \mathrm{~Bq} / \mathrm{kg}$ for the $0.5 \mathrm{~g}$ small sample size. This detection limit is appropriate for the phosphate samples with high activity concentration $(>200 \mathrm{~Bq} / \mathrm{kg})$. An ultra-low-level liquid scintillation spectrometer, Quantulus model 1220 from PerkinElmer was used for measuring ground water samples in addition to the $\alpha$-spectrometry system.

\section{Radiotracers}

${ }^{232}$ Uranium and ${ }^{229} \mathrm{Th}$ standard reference materials, SRM 4324 and SRM 4328C, respectively, were purchased from the National Institute of Standards and Technology (NIST). The standard materials were diluted and used as spiking radiotracers in uranium and thorium determinations.

\section{Results and discussion}

The collected phosphate rock, phosphate waste, and topsoil samples from the mining site A, were analysed, and the obtained results are listed in Tables 2-4. Table 2 shows the activity concentration of the high-grade ore and its physical beneficiation products.

Data in Table 2 indicate that the activity concentration of ${ }^{238} \mathrm{U}$ in the high-grade phosphate ore and the beneficiation products (raw rock, phosphate concentrate, and phosphate reject) ranges from $350 \mathrm{~Bq} / \mathrm{kg}$ to $454 \mathrm{~Bq} / \mathrm{kg}$ in raw rocks, $399 \mathrm{~Bq} / \mathrm{kg}$ to $622 \mathrm{~Bq} / \mathrm{kg}$ in phosphate concentrate, and $327 \mathrm{~Bq} / \mathrm{kg}$ to $378 \mathrm{~Bq} / \mathrm{kg}$ in phosphate reject. The average value of activity concentration is $378 \pm 19 \mathrm{~Bq} / \mathrm{kg}$ in raw rocks, $502 \pm 25 \mathrm{~Bq} / \mathrm{kg}$ in phosphate concentrate, and $352 \pm 16 \mathrm{~Bq} / \mathrm{kg}$ in phosphate reject. The values indicate that there is a difference in uranium concentration between the raw ore, concentrate, and reject samples. This trend of values is in agreement with that of $\mathrm{P}_{2} \mathrm{O}_{5}$ concentration in the samples indicating that uranium is distributed homogeneously in different components of the phosphate deposits around this area. The observed average ${ }^{234} \mathrm{U} /{ }^{238} \mathrm{U}$ activity ratio is slightly greater than unity (about 1.1) in almost all samples, which is commonly found in phosphate deposits of sedimentary origin $[13,15,25,26]$. The range of activity concentration of ${ }^{232} \mathrm{Th}$ is between $4 \mathrm{~Bq} / \mathrm{kg}$ and $11 \mathrm{~Bq} / \mathrm{kg}$ with an average value of $8 \pm 6 \mathrm{~Bq} / \mathrm{kg}$, which is far below that of ${ }^{238} \mathrm{U}$. Additionally, ${ }^{234} \mathrm{U}$ and ${ }^{230} \mathrm{Th}$ almost attained radioactive equilibrium. These findings are common in most phosphate deposits of sedimentary origin.

Considering that ${ }^{238} \mathrm{U}$ and ${ }^{226} \mathrm{Ra}$ are in radioactive equilibrium, the average concentrations of ${ }^{238} \mathrm{U}$ and 
Table 2. Activity concentration of uranium and thorium in high-grade raw phosphate ore and its physical beneficiation products (concentrate and reject)

\begin{tabular}{|c|c|c|c|c|c|}
\hline \multirow{3}{*}{ Sample } & \multicolumn{5}{|c|}{ Activity concentration $(\mathrm{Bq} / \mathrm{kg})$} \\
\hline & \multicolumn{2}{|c|}{$\mathrm{U}$ isotopes } & \multicolumn{3}{|c|}{ Th isotopes } \\
\hline & ${ }^{238} \mathrm{U}$ & ${ }^{234} \mathrm{U}$ & ${ }^{232} \mathrm{Th}$ & ${ }^{230} \mathrm{Th}$ & ${ }^{228} \mathrm{Th}$ \\
\hline \multirow[t]{9}{*}{ Raw rock } & $350 \pm 35$ & $396 \pm 49$ & $6 \pm 1$ & $388 \pm 48$ & $5 \pm 2$ \\
\hline & $351 \pm 47$ & $375 \pm 50$ & $9 \pm 3$ & $348 \pm 53$ & $8 \pm 3$ \\
\hline & $367 \pm 46$ & $406 \pm 41$ & $10 \pm 3$ & $325 \pm 42$ & $7 \pm 2$ \\
\hline & $454 \pm 33$ & $468 \pm 38$ & $8 \pm 2$ & $489 \pm 36$ & $8 \pm 2$ \\
\hline & $389 \pm 46$ & $411 \pm 42$ & $8 \pm 1$ & $422 \pm 43$ & $9 \pm 2$ \\
\hline & $364 \pm 33$ & $358 \pm 32$ & $11 \pm 3$ & $349 \pm 52$ & $12 \pm 2$ \\
\hline & $353 \pm 36$ & $388 \pm 45$ & $4 \pm 1$ & $345 \pm 43$ & $3 \pm 2$ \\
\hline & $367 \pm 36$ & $375 \pm 45$ & $7 \pm 2$ & $382 \pm 43$ & $6 \pm 3$ \\
\hline & $405 \pm 58$ & $423 \pm 61$ & $7 \pm 2$ & $395 \pm 57$ & $8 \pm 2$ \\
\hline Average & $378 \pm 19$ & $400 \pm 20$ & $8 \pm 5$ & $383 \pm 18$ & $7 \pm 4$ \\
\hline $\mathrm{CV}^{*}$ & 5 & 5 & 62.5 & 4.7 & 57.1 \\
\hline \multirow[t]{12}{*}{ Concentrate } & $459 \pm 47$ & $471 \pm 49$ & $7 \pm 1$ & $463 \pm 36$ & $5 \pm 2$ \\
\hline & $542 \pm 55$ & $569 \pm 57$ & $5 \pm 2$ & $520 \pm 41$ & $4 \pm 2$ \\
\hline & $557 \pm 53$ & $568 \pm 55$ & $11 \pm 3$ & $544 \pm 49$ & $7 \pm 2$ \\
\hline & $442 \pm 45$ & $466 \pm 45$ & $10 \pm 2$ & $430 \pm 47$ & $9 \pm 2$ \\
\hline & $475 \pm 48$ & $578 \pm 58$ & $6 \pm 2$ & $548 \pm 54$ & $8 \pm 2$ \\
\hline & $622 \pm 59$ & $684 \pm 61$ & $7 \pm 2$ & $671 \pm 66$ & $8 \pm 2$ \\
\hline & $399 \pm 48$ & $413 \pm 46$ & $4 \pm 1$ & $385 \pm 50$ & $4 \pm 2$ \\
\hline & $555 \pm 56$ & $540 \pm 54$ & $5 \pm 2$ & $697 \pm 56$ & $4 \pm 2$ \\
\hline & $439 \pm 54$ & $485 \pm 59$ & $6 \pm 2$ & $466 \pm 49$ & $4 \pm 2$ \\
\hline & $488 \pm 48$ & $491 \pm 51$ & $8 \pm 2$ & $454 \pm 50$ & $6 \pm 2$ \\
\hline & $539 \pm 57$ & $566 \pm 59$ & $5 \pm 2$ & $525 \pm 47$ & $4 \pm 2$ \\
\hline & $503 \pm 50$ & $526 \pm 57$ & $9 \pm 2$ & $478 \pm 47$ & $7 \pm 2$ \\
\hline Average & $502 \pm 25$ & $530 \pm 25$ & $7 \pm 2$ & $515 \pm 24$ & $6 \pm 2$ \\
\hline $\mathrm{CV}^{*}$ & 5 & 4.72 & 28.57 & 4.66 & 33.33 \\
\hline \multirow[t]{6}{*}{ Reject } & $327 \pm 43$ & $365 \pm 43$ & $5 \pm 2$ & $371 \pm 45$ & $5 \pm 3$ \\
\hline & $378 \pm 42$ & $383 \pm 43$ & $6 \pm 2$ & $376 \pm 39$ & $7 \pm 2$ \\
\hline & $366 \pm 47$ & $412 \pm 48$ & $5 \pm 2$ & $346 \pm 50$ & $6 \pm 2$ \\
\hline & $355 \pm 41$ & $403 \pm 44$ & $6 \pm 2$ & $563 \pm 46$ & $6 \pm 2$ \\
\hline & $337 \pm 44$ & $394 \pm 47$ & $5 \pm 1$ & $386 \pm 39$ & $5 \pm 2$ \\
\hline & $346 \pm 42$ & $344 \pm 43$ & $5 \pm 2$ & $361 \pm 46$ & $7 \pm 2$ \\
\hline Average & $352 \pm 16$ & $384 \pm 16$ & $5 \pm 3$ & $401 \pm 16$ & $6 \pm 4$ \\
\hline $\mathrm{CV}^{*}$ & 4.55 & 4.71 & 60 & 4 & 66.67 \\
\hline
\end{tabular}

$* \mathrm{CV}=$ coefficient of variation $=($ standard deviation/average value $) \times 100$.

${ }^{226} \mathrm{Ra}$ in this work are equivalent to $513.1 \pm 2.5 \mathrm{~Bq} /$ $\mathrm{kg}$ and $39.1 \pm 1.5 \mathrm{~Bq} / \mathrm{kg}$, respectively, as previously reported in phosphate samples collected from a site located northwest of Saudi Arabia [20]. This site is an extension of the phosphate deposits that spread from the north eastern to the north western region in Saudi Arabia.

The feed and products of the low-grade ore and the beneficiation plant were analysed, and their activity concentration results are shown in Table 3. All samples were collected at the mining site, site A. Data in Table 3 indicates that the activity concentration of ${ }^{238} \mathrm{U}$ in the low-grade ore ranges from $243 \mathrm{~Bq} / \mathrm{kg}$ to $316 \mathrm{~Bq} / \mathrm{kg}$, with an average value of $280 \pm 11 \mathrm{~Bq} / \mathrm{kg}$. This average seems to be lower than that of the high-grade ore of $378 \pm 19 \mathrm{~Bq} / \mathrm{kg}$. The average activity concentration of ${ }^{238} \mathrm{U}$ in the produced concentrates and rejects ranges from $390 \mathrm{~Bq} / \mathrm{kg}$ to $508 \mathrm{~Bq} / \mathrm{kg}$, and from $62 \mathrm{~Bq} / \mathrm{kg}$ to $113 \mathrm{~Bq} / \mathrm{kg}$, with average values of $440 \pm 19 \mathrm{~Bq} / \mathrm{kg}$ and $87 \pm 6 \mathrm{~Bq} /$ $\mathrm{kg}$, respectively. The ${ }^{238} \mathrm{U}$ activity concentrations in the concentrates produced from low and high-grade ores (Tables 2 and 3 ) are equivalent and almost the same. This trend of values is in agreement with that of $\mathrm{P}_{2} \mathrm{O}_{5}$ concentration in the samples (concentrate $>$ ore $>$ reject), because of the homogeneous distribution of uranium in the different formation of the phosphate deposits.

Even though the activity concentration of ${ }^{232} \mathrm{Th}$ is far below that of ${ }^{238} \mathrm{U}$, it is similar to the values observed in the other published studies [13,26]. The activity concentration of uranium listed in Tables 2 and 3 is less than by one order of magnitude when compared to the proposed IAEA value of 2460 $\mathrm{Bq} / \mathrm{kg}$. Therefore, the uranium content in the concentrate samples of Al-Jalamid phosphate deposits cannot be processed for economic benefits as it is not commercially viable. Additionally, the chemical phosphate beneficiation process produces reject with low uranium content as well.

Uranium and thorium were analysed in the topsoil and in the waste layers of the mining area in site $\mathrm{A}$ and the activity concentration results are given in Table 4. 
Table 3. Activity concentration of uranium and thorium in low-grade raw phosphate ore and the chemical beneficiation products (concentrate and reject)

\begin{tabular}{|c|c|c|c|c|c|}
\hline \multirow{3}{*}{ Sample } & \multicolumn{5}{|c|}{ Activity concentration $(\mathrm{Bq} / \mathrm{kg})$} \\
\hline & \multicolumn{2}{|c|}{ U isotopes } & \multicolumn{3}{|c|}{ Th isotopes } \\
\hline & ${ }^{238} \mathrm{U}$ & ${ }^{234} \mathrm{U}$ & ${ }^{232} \mathrm{Th}$ & ${ }^{230} \mathrm{Th}$ & ${ }^{228} \mathrm{Th}$ \\
\hline \multirow[t]{4}{*}{ Raw rock } & $293 \pm 30$ & $260 \pm 23$ & $9 \pm 2$ & $267 \pm 18$ & $7 \pm 2$ \\
\hline & $243 \pm 26$ & $255 \pm 30$ & $6 \pm 2$ & $256 \pm 19$ & $7 \pm 3$ \\
\hline & $268 \pm 32$ & $253 \pm 27$ & $6 \pm 2$ & $251 \pm 22$ & $6 \pm 3$ \\
\hline & $316 \pm 34$ & $274 \pm 31$ & $8 \pm 3$ & $298 \pm 18$ & $7 \pm 3$ \\
\hline Average & $280 \pm 11$ & $261 \pm 10$ & $7 \pm 3$ & $268 \pm 9$ & $7 \pm 3$ \\
\hline $\mathrm{CV}^{*}$ & 3.93 & 3.83 & 42.86 & 3.36 & 42.86 \\
\hline \multirow[t]{7}{*}{ Concentrate } & $393 \pm 52$ & $421 \pm 54$ & $6 \pm 2$ & $408 \pm 58$ & $7 \pm 2$ \\
\hline & $508 \pm 55$ & $534 \pm 61$ & $8 \pm 2$ & $601 \pm 64$ & $8 \pm 2$ \\
\hline & $436 \pm 63$ & $416 \pm 60$ & $10 \pm 2$ & $430 \pm 47$ & $8 \pm 2$ \\
\hline & $422 \pm 52$ & $414 \pm 51$ & $7 \pm 2$ & $437 \pm 54$ & $6 \pm 2$ \\
\hline & $390 \pm 46$ & $417 \pm 45$ & $7 \pm 2$ & $382 \pm 53$ & $6 \pm 2$ \\
\hline & $440 \pm 46^{* * *}$ & $457 \pm 45$ & $7 \pm 2$ & $446 \pm 51$ & $6 \pm 2$ \\
\hline & $490 \pm 55^{* * *}$ & $486 \pm 61$ & $11 \pm 2$ & $430 \pm 47$ & $8 \pm 2$ \\
\hline Average & $440 \pm 19$ & $449 \pm 19$ & $8 \pm 4$ & $448 \pm 19$ & $7 \pm 4$ \\
\hline $\mathrm{CV}^{*}$ & 4.32 & 4.23 & 50 & 4.24 & 57.14 \\
\hline \multirow[t]{5}{*}{ Reject } & $86 \pm 7$ & $82 \pm 7$ & $3 \pm 2$ & $92 \pm 8$ & $2 \pm 1$ \\
\hline & $97 \pm 7$ & $91 \pm 7$ & $4 \pm 2$ & $103 \pm 9$ & $5 \pm 2$ \\
\hline & $62 \pm 7$ & $68 \pm 6$ & $3 \pm 1$ & $75 \pm 7$ & $3 \pm 2$ \\
\hline & $113 \pm 12$ & $96 \pm 9$ & $5 \pm 2$ & $101 \pm 10$ & $4 \pm 2$ \\
\hline & $78 \pm 9$ & $91 \pm 9$ & $4 \pm 2$ & $88 \pm 11$ & $5 \pm 2$ \\
\hline Average & $87 \pm 6$ & $86 \pm 6$ & $4 \pm 3$ & $92 \pm 6$ & $4 \pm 3$ \\
\hline $\mathrm{CV}^{*}$ & 6.9 & 6.98 & 75 & 6.52 & 75 \\
\hline
\end{tabular}

$* \mathrm{CV}=$ coefficient of variation $=($ standard deviation/average value $) \times 100$.

***Dust samples.

Table 4. Activity concentrations of uranium and thorium in the topsoil and waste layers

\begin{tabular}{|c|c|c|c|c|c|}
\hline \multirow{3}{*}{ Sample } & \multicolumn{5}{|c|}{ Activity concentration $(\mathrm{Bq} / \mathrm{kg})$} \\
\hline & \multicolumn{2}{|c|}{ U isotopes } & \multicolumn{3}{|c|}{ Th isotopes } \\
\hline & ${ }^{238} \mathrm{U}$ & ${ }^{234} \mathrm{U}$ & ${ }^{232} \mathrm{Th}$ & ${ }^{230} \mathrm{Th}$ & ${ }^{228} \mathrm{Th}$ \\
\hline \multirow[t]{6}{*}{ Topsoil } & $47 \pm 8$ & $51 \pm 8$ & $137 \pm 13$ & $46 \pm 4$ & $129 \pm 11$ \\
\hline & $89 \pm 9$ & $82 \pm 9$ & $66 \pm 8$ & $63 \pm 7$ & $67 \pm 7$ \\
\hline & $61 \pm 8$ & $66 \pm 10$ & $112 \pm 10$ & $71 \pm 8$ & $104 \pm 10$ \\
\hline & $44 \pm 7$ & $40 \pm 7$ & $135 \pm 11$ & $47 \pm 6$ & $111 \pm 10$ \\
\hline & $96 \pm 10$ & $110 \pm 10$ & $86 \pm 9$ & $114 \pm 10$ & $96 \pm 9$ \\
\hline & $59 \pm 7$ & $55 \pm 7$ & $97 \pm 10$ & $56 \pm 7$ & $95 \pm 10$ \\
\hline Average & $66 \pm 7$ & $67 \pm 7$ & $106 \pm 8$ & $66 \pm 6$ & $100 \pm 8$ \\
\hline $\mathrm{CV}^{*}$ & 10.61 & 10.45 & 7.55 & 9.1 & 8 \\
\hline Overburden waste & $64 \pm 6$ & $68 \pm 7$ & $12 \pm 3$ & $63 \pm 5$ & $13 \pm 3$ \\
\hline \multirow[t]{4}{*}{ layer } & $52 \pm 6$ & $57 \pm 6$ & $9 \pm 2$ & $48 \pm 6$ & $9 \pm 2$ \\
\hline & $55 \pm 7$ & $62 \pm 9$ & $7 \pm 2$ & $56 \pm 5$ & $7 \pm 2$ \\
\hline & $85 \pm 7$ & $86 \pm 7$ & $9 \pm 2$ & $82 \pm 9$ & $8 \pm 2$ \\
\hline & $71 \pm 6$ & $76 \pm 6$ & $12 \pm 3$ & $77 \pm 8$ & $11 \pm 3$ \\
\hline Average & $65 \pm 6$ & $70 \pm 6$ & $10 \pm 3$ & $65 \pm 6$ & $10 \pm 3$ \\
\hline $\mathrm{CV}^{*}$ & 9.23 & 8.57 & 30 & 9.23 & 30 \\
\hline Intermediate waste & $312 \pm 25$ & $311 \pm 25$ & $5 \pm 2$ & $290 \pm 27$ & $5 \pm 2$ \\
\hline \multirow[t]{4}{*}{ layer } & $177 \pm 18$ & $189 \pm 19$ & $4 \pm 2$ & $168 \pm 11$ & $4 \pm 2$ \\
\hline & $150 \pm 14$ & $160 \pm 16$ & $5 \pm 2$ & $174 \pm 12$ & $5 \pm 2$ \\
\hline & $214 \pm 21$ & $234 \pm 23$ & $6 \pm 2$ & $222 \pm 13$ & $5 \pm 2$ \\
\hline & $263 \pm 22$ & $276 \pm 26$ & $4 \pm 2$ & $271 \pm 15$ & $5 \pm 3$ \\
\hline Average & $223 \pm 10$ & $234 \pm 10$ & $5 \pm 3$ & $225 \pm 9$ & $5 \pm 3$ \\
\hline $\mathrm{CV}^{*}$ & 4.48 & 4.27 & 60 & 4 & 60 \\
\hline
\end{tabular}

$* \mathrm{CV}=$ coefficient of variation $=($ standard deviation/average value $) \times 100$. 
The concentration of ${ }^{238} \mathrm{U}$ is $223 \pm 10 \mathrm{~Bq} / \mathrm{kg}$ in the intermediate waste layer, which is higher than that of the topsoil layer with an activity concentration of $66 \pm 7 \mathrm{~Bq} / \mathrm{kg}$, and the overburden waste layer with an activity concentration of $65 \pm$ $6 \mathrm{~Bq} / \mathrm{kg}$ even though the intermediate waste layer has the lowest ${ }^{232} \mathrm{Th}$ content at $5 \pm 3 \mathrm{~Bq} / \mathrm{kg}$. The intermediate waste layer is mostly carbonate with some phosphate and other waste materials. Topsoil material (natural soil) contains the highest ${ }^{232} \mathrm{Th}$ content $(106 \pm 8 \mathrm{~Bq} / \mathrm{kg})$ compared to other layers of phosphate or waste $(<11 \mathrm{~Bq} / \mathrm{kg})$, which is expected in natural soil. Usually, the concentrations of uranium and thorium are found to be significant in natural soil ranging from $25 \mathrm{~Bq} / \mathrm{kg}$ to $60 \mathrm{~Bq} / \mathrm{kg}$ [27]. This generalization is cannot be found in the present samples. Comparing the results of ${ }^{238} \mathrm{U}$ and ${ }^{232} \mathrm{Th}$ with that of normal soil listed in Table 4, it is clear that the samples are enriched in uranium and depleted in thorium. This shows the same trend in the phosphate ore despite the fact that it has lower uranium concentrations.

The ${ }^{238} \mathrm{U}$ content in the topsoil and overburden waste layers is $65 \pm 6 \mathrm{~Bq} / \mathrm{kg}$ although their ${ }^{232} \mathrm{Th}$ content was quite different. Additionally, data in Table 4 shows almost radioactive equilibrium between ${ }^{238} \mathrm{U}$ and ${ }^{230} \mathrm{Th}$ isotopes, both belonging to the uranium series, and between ${ }^{232} \mathrm{Th}$ and ${ }^{228} \mathrm{Th}$, which are members of thorium series, in the topsoil and waste samples. The average concentration of ${ }^{232} \mathrm{Th}$ is higher in the topsoil samples when compared to the ore and while in the waste samples, it is still high compared to its average concentration in normal soil. This is likely due to mixing of overburden waste and topsoil layers with phosphate and carbonate deposits.

This trend in results is consistent with that reported by [15], which reported that activity concen-

Table 5. International values (averages) for ${ }^{238} \mathrm{U}$ and ${ }^{232} \mathrm{Th}$ in different phosphate deposits of the Tethys Sea

\begin{tabular}{lcc}
\hline \multirow{2}{*}{ Country } & \multicolumn{2}{c}{ Activity concentration $(\mathrm{Bq} / \mathrm{kg})$} \\
\cline { 2 - 3 } & ${ }^{238} \mathrm{U}$ & ${ }^{232} \mathrm{Th}$ \\
\hline Al-Jalamid, Saudi & $378 \pm 125$ & $8 \pm 6$ \\
$\quad$ Arabia, this study & - & 39 \\
Saudi Arabia [20] & - & 2 \\
Jordan [28] & $1300-1850$ & - \\
Jordan [26] & - & 19 \\
Jordan [4] & - & 11 \\
Israel [28] & $1500-1700$ & - \\
Israel [26] & - & 395 \\
Egypt [29] & - & $19 \pm 2$ \\
Egypt [18] & 408 & 23.7 \\
Egypt [30] & - & 29 \\
Tunisia [28] & - & 64 \\
Algeria [28] & 1700 & 30 \\
Morocco [26] & 1500 & 30 \\
Morocco [26] & 1700 & 20 \\
Morocco [13] & 1600 & 10 \\
Morocco [19] & 900 & 7 \\
Sahara Western [13] & 1000 & - \\
USA (Florida) [19] & 1500 & 20 \\
USA (Florida) [13] & & \\
\hline & &
\end{tabular}

tration of ${ }^{238} \mathrm{U}$ and ${ }^{232} \mathrm{Th}$ ranged from $684 \mathrm{~Bq} / \mathrm{kg}$ to $2598 \mathrm{~Bq} / \mathrm{kg}$ and from $0.8 \mathrm{~Bq} / \mathrm{kg}$ to $2.5 \mathrm{~Bq} / \mathrm{kg}$, respectively, in ore samples. The study also reported that activity concentration of ${ }^{238} \mathrm{U}$ and ${ }^{232} \mathrm{Th}$ in ground samples were $16 \mathrm{~Bq} / \mathrm{kg}$ to $77 \mathrm{~Bq} / \mathrm{kg}$ and from $7.6 \mathrm{~Bq} / \mathrm{kg}$ to $43.2 \mathrm{~Bq} / \mathrm{kg}$, respectively. The data trend shows lower concentration of ${ }^{232} \mathrm{Th}$ in phosphate rock than in the ground soil, especially topsoil. Uranium and thorium data in the phosphate deposits are more meaningful when the obtained values are compared with other values for the phosphate sediments of the Tethys Sea from other countries. Table 5 summarizes most of these previous reported values.

Values obtained from this work are about 2-3 times lower than those reported by other studies conducted in Morocco and Jordan [13, 19, 26].

More studies were conducted in various parts of the world and the results excluding the Tethys Sea are listed in Table 6.

Activity concentrations listed in Table 6 indicate that values of Russia, China, and Finland, are far below the values reported for the phosphate deposits of Tethys Sea [12-14] and are comparable with that in natural soil. But, the values from South Africa, Sudan, Tanzania, and western USA are several times higher [15]. These values exceeded the IAEA threshold of $200 \mathrm{ppm}(2460 \mathrm{~Bq} / \mathrm{kg})$ for uranium concentration in the phosphate rocks, which qualifies these ores for commercial and economical recovery of uranium. This wide range of uranium and thorium concentrations and ${ }^{238} \mathrm{U}$ to ${ }^{232} \mathrm{Th}$ activity ratios in the different phosphate deposits around the globe are mostly related to differences in the geological nature of the region/mine site.

As for the groundwater samples, they were analysed using the $\alpha$-spectrometer and the liquid scintillation counter utilizing gross alpha and gross beta methods. Sample results demonstrate increased levels of natural radioactivity that requires treatment procedures before the water can be used for human consumption as reported in [35].

Table 6. International values for ${ }^{238} \mathrm{U}$ and ${ }^{232} \mathrm{Th}$ in phosphate sedimentary rocks of different countries excluding the Tethys Sea

\begin{tabular}{lcc}
\hline \multirow{2}{*}{ Country } & \multicolumn{2}{c}{ Activity concentration $(\mathrm{Bq} / \mathrm{kg})$} \\
\cline { 2 - 3 } & ${ }^{238} \mathrm{U}$ & ${ }^{232} \mathrm{Th}$ \\
\hline Sudan (Kurun) [15] & 684 & 0.83 \\
Sudan (Uro) [15] & 2598 & 2.5 \\
Sudan [31] & - & 7.5 \\
Tanzania (Arusha) [25] & 4641 & 717 \\
South Africa (Togo) [13] & 1300 & 30 \\
South Africa (Togo) [26] & 1300 & 110 \\
USA (Western) [13] & 1000 & 20 \\
USA (South Carolina) [32] & 4800 & - \\
Brazil [33] & - & 3238 \\
Russia (Kola) [13] & 40 & 80 \\
Russia (Kola) [26] & 90 & - \\
Russia (Kola) [14] & 30 & 80 \\
Pakistan (Hazara) [4] & - & 48 \\
Pakistan [34] & 440 & 50 \\
China [26] & 150 & - \\
Finland [12] & 10 & 10 \\
\hline
\end{tabular}




\section{Conclusions}

In conclusion, this work estimated radiation exposure and dose levels in Al-Jalamid site in northern Saudi Arabia. The activity concentration of ${ }^{238} \mathrm{U}$ in Al-Jalamid phosphate deposits shows intermediate levels when compared with other reported values for sedimentary phosphate deposits worldwide. However, the activity concentration of the phosphate deposits in the site is of low value when compared to other reported values for the phosphate deposits in the same Tethys Sea area. The study concludes that the average activity concentration of natural uranium in phosphate concentrate is less than the value $2460 \mathrm{~Bq} / \mathrm{kg}$ as set by IAEA, it cannot be recommended for its potential economic recovery. The levels of ${ }^{232} \mathrm{Th}$ are found to be far below that of uranium in phosphate deposits, and lower than that of natural topsoil. Further, ${ }^{238} \mathrm{U}$ and ${ }^{232} \mathrm{Th}$ are in a state of radioactive equilibrium with their respective decay products. Ground water analysis revealed increased levels of natural radioactivity and must undergo a treatment procedure before it can be used for human consumption. Sample analyses determined that radiation exposure levels in the mining area are safe for personnel working at the mine site.

Acknowledgment. This work was funded by the National Plan for Science, Technology and Innovation (MAARIFAH), King Abdulaziz City for Science and Technology, Kingdom of Saudi Arabia (Award No. 11-ENV2058-03). The authors also acknowledge and thank Science and Technology Unit, King Abdulaziz University for their technical support.

\section{ORCID}

A. M. Alhawsawi (D) http://orcid.org/0000-0002-7992-8850 E. M. Banoqitah (D)http://orcid.org/0000-0002-9127-6322

\section{References}

1. Diammonium phosphate (DAP) production from Saudi Arabian phosphate deposits. (2003). Materials World, 11(5), 23-24. Retrieved from https://www. azom.com/article.aspx? ArticleID $=2083$.

2. Atta, E. R., Zakaria, K. M., \& Ibrahim M. S. (2016). Assessment of the heavy metals and natural radioactivity in phosphate mines and occupational health effects at some Egyptian regions. J. Environ. Prot. (Irvine,. Calif)., 7(11), 1657-1669.

3. Sahu, S. K., Ajmal, P. Y., Bhangare, R. C., Tiwari, M., \& Pandit, G. G. (2014). Natural radioactivity assessment of a phosphate fertilizer plant area. J. Radiat. Res. Appl. Sci., 7(1), 123-128.

4. Tufail, M., Akhtar, N., \& Waqas, M. (2006). Radioactive rock phosphate: the feed stock of phosphate fertilizers used in Pakistan. Health Phys., 90(4), 361-370.

5. Fávaro, D. I. T. (2005). Natural radioactivity in phosphate rock, phosphogypsum and phosphate fer- tilizers in Brazil. J. Radioanal. Nucl. Chem., 264(2), 445-448.

6. Azouazi, M., Ouahidi, Y., Fakhi, S., Andres, Y., Abbe, J. C., \& Benmansour, M. (2001). Natural radioactivity in phosphates, phosphogypsum and natural waters in Morocco. J. Environ. Radioact., 54(2), 231-242.

7. Papastefanou, C. (2001). Radiological impact from atmospheric releases of ${ }^{238} \mathrm{U}$ and ${ }^{226} \mathrm{Ra}$ from phosphate rock processing plants. J. Environ. Radioact., 54(1), 75-83.

8. Banzi, F. P., Kifanga, L. D., \& Bundala, F. M. (2000). Natural radioactivity and radiation exposure at the Minjingu phosphate mine in Tanzania. J. Radiol. Prot., 20(1), 41-51.

9. Menzel, R. G. (1968). Uranium, radium, and thorium content in phosphate rocks and their possible radiation hazard. J. Agric. Food Chem., 16(2), 231-234.

10. Zapata, F. \& Roy, R. N. (Eds.). (2004). Use of phosphate rocks for sustainable agriculture. Rome: FAO/ IAEA. (FAO Fertilizer and Plant Nutrition Bulletin no. 13). Available from http://www.fao.org/3/y5053e/ y5053e00.htm\#Contents.

11. Komura, K., Yanagisawa, M., Sakurai, J., \& Sakanoue, M. (1985). Uranium, thorium and potassium contents and radioactive equilibrium states of the uranium and thorium series nuclides in phosphate rocks and phosphate fertilizers. Radioisotopes, 34(10), 529-36. https://doi.org/10.3769/radioisotopes.34.10_529.

12. Mustonen, $\bar{R}$. (1985). Radioactivity of fertilizers in Finland. Sci. Total Environ., 45, 127-134.

13. Guimond, R. J. (1990). Radon in fertilizers. In The environmental behaviour of radium (Vol. 2, pp. 113-128). Vienna: International Atomic Energy Agency (Technical Reports Series no. 310). Available from https://inis.iaea.org/collection/NCLCollectionStore/ Public/21/052/21052628.pdf? $\mathrm{r}=1 \& \mathrm{r}=1$.

14. Pfister, H., Philipp, G., \& Pauly, H. (1976). Population dose from natural radionuclides in phosphate fertilizers. Radiat. Environ. Biophys., 13(3), 247-261.

15. Sam, A., \& Holm, E. (1995). The natural radioactivity in phosphate deposits from Sudan. Sci. Total Environ., 162(2/3), 173-178.

16. International Atomic Energy Agency. (1979). Gammaray surveys in uranium exploration. Vienna: IAEA. (Technical Report Series no. 186). Available from https://inis.iaea.org/collection/NCLCollectionStore/ Public/10/454/10454955.pdf?r=1\&r=1.

17. Kennedy, R. H. (1967). Recovery of uranium from low-grade sandstone ores and phosphate rock. In Processing of low-grade uranium ores (pp. 216-226). Vienna: IAEA. Available from https://www-pub.iaea. org/MTCD/Publications/PDF/Pub146 web.pdf.

18. Hassan, N. M., Mansour, N. A., Fayez-Hassan, M., \& Sedqy, E. (2015). Assessment of natural radioactivity in fertilizers and phosphate ores in Egypt. J. Taibah Univ. Sci., 10(2), 296-306.

19. Guimond, R. J., \& Hardin, J. M. (1989). Radioactivity released from phosphate-containing fertilizers and from gypsum. Int. J. Radiat. Appl. Instrum. Part CRadiat. Phys. Chem., 34(2), 309-315.

20. Al Zahrani, J. H., Alharbi, W. R., \& Abbady, A. G. E. (2011). Radiological impacts of natural radioactivity and heat generation by radioactive decay of phosphorite 
deposits from northwestern Saudi Arabia. Australian Journal of Basic and Applied Sciences, 5(6), 683-690.

21. Shabana, A. A., Banoqitah, E. I., Qutub, E. M., Tayeb, M. M. T., \& Kinsara, M. S. (2019). Evaluation of radiation hazards due to mining activities in $\mathrm{Al}$ Jalamid mining area, North Province, Saudi Arabia. Arab. J. Sci. Eng., 44, 8799-8804. https://doi.org/10.1007/ s13369-019-03840-8.

22. Wallace, C. A., Dini, S. M., \& Al-Farasani, A. A. (2003). Geologic map of the Hazm Al Jalamid Quadrangle, Sheet 31D, and part of the Markaz 'Anazah quadrangle, Sheet $32 \mathrm{D}$ with explanatory notes. Saudi Geological Survey.

23. Shabana, E. I., \& Al-Hobaib, A. S. (1999). Activity concentrations of natural radium, thorium and uranium isotopes in ground water of two different regions. Radiochim. Acta, 87(1/2), 41-45.

24. International Atomic Energy Agency. (2004). Analytical Quality Control Services (AQCS), reference materials catalogue. Vienna: IAEA.

25. Makweba, M. M., \& Holm, E. (1993). The natural radioactivity of the rock phosphates, phosphatic products and their environmental implications. Sci. Total Environ., 133(1/2), 99-110.

26. UNSCEAR. (1982). Ionizing radiation: sources and biological effects. UNSCEAR 1982 Report. US Scientific Committee on the Effects of Atomic Radiation. Available from https://www.unscear.org/unscear/en/ publications/1982.html.

27. UNSCEAR. (2000). Sources and effects of ionizing radiation. UNSCEAR 2000 Report. Vol. 1. UN Scientific Committee on the Effects of Atomic Radiation. Available from https://www.unscear.org/docs/publications/2000/UNSCEAR_2000_Report_Vol.I.pdf.

\section{Appendix A}

\section{Determination of uranium isotopes}

Dry prescribed amount of the soil, for approximately $3 \mathrm{~h}$, at $105^{\circ} \mathrm{C}$ in a drying oven. Grind and sieve the soil (100 mesh), then ash in silica dish for about $20 \mathrm{~h}$, at $550^{\circ} \mathrm{C}$. Measure the weight equivalent to $1 \mathrm{~g}$ of dry soil. Spike an appropriate weight of the ached sample with $500 \mu \mathrm{L}$ of ${ }^{232} \mathrm{U}$ tracer $(10-15 \mathrm{dpm} / \mathrm{mL})$ in $250-\mathrm{mL}$ Teflon beaker. Digest with $\left(\mathrm{HNO}_{3}-\mathrm{HClO}_{4}{ }^{-}\right.$ $\mathrm{HF}$ ) to dissolve, then evaporate to dryness and dissolve the salt in concentrated $\mathrm{HCl}$. Add concentrated acid to obtain a final sample solution $20 \mathrm{~mL}$ in $10 \mathrm{M} \mathrm{HCl}$

\section{Anion exchange separation of $U$}

- Pack a small column (10 mL in volume) with the resin (AG 1-X8) by adding its slurry in distilled water to the column when it is also filled with distilled water to occupy $5 \mathrm{~mL}$ as a bed volume.

- Condition the column by passing about $20 \mathrm{~mL}$ of $10 \mathrm{M} \mathrm{HCl}$ through the resin. Discard the effluent.

- Load the sample solution to the column, and then wash the resin with excess $20 \mathrm{~mL}$ of $10 \mathrm{M} \mathrm{HCl}$. Discard the effluents.
28. Olszewska-Wasiolek, M. (1995). Estimates of the occupational radiological hazard in the phosphate fertilizers industry in Poland. Radiat. Prot. Dosim., 58, 269-276.

29. El-Taher, A., \& Makhluf, S. (2010). Natural radioactivity levels in phosphate fertilizer and its environmental implications in assuit governorate, upper Egypt. Indian J. Pure Appl. Phys., 48(10), 697-702.

30. Khater, A. E. M., Higgy, R., \& Pimpl, M. (2001). Radiological impacts of natural radioactivity in Abu-Tartor phosphate deposits, Egypt. J. Environ. Radioact., 55(3), 255-267.

31. Sam, A. K., Ahamed, M. M. O., El Khangi, F. A., El Nigumi, Y. O., \& Holm, E. (1999). Radiological and chemical assessment of Uro and Kurun rock phosphates. J. Environ. Radioact., 42(1), 65-75.

32. Scholten, L. C., \& Timmermans, C. W. M. (1996). Natural radioactivity in phosphate fertilizers. Fertil. Res., 43(1/3), 103-107.

33. Da Conceição, F. T., \& Bonotto, D. M. (2006). Radionuclides, heavy metals and fluorine incidence at Tapira phosphate rocks, Brazil, and their industrial (by) products. Environ. Pollut., 139(2), 232-243.

34. Khan, K., Khan, H. M., Tufail, M., Khatibeh, A. J. A. H., \& Ahmad, N. (1998). Radiometric analysis of Hazara phosphate rock and fertilizers in Pakistan. J. Environ. Radioact., 38(1), 77-84.

35. Shabana, E. -S. I., Banoqitah, E. M., Qutub, M. M. T., Tayeb, M. S., \& Kinsara, A. A. (2019). Evaluation of radiation hazards due to mining activities in $\mathrm{Al}$ Jalamid mining area, North Province, Saudi Arabia. Arab. J. Sci. Eng., . 44, 8799-8804.

- In a clean beaker, elute U from the column by passing $20 \mathrm{~mL}$ of $0.1 \mathrm{M} \mathrm{HCl}$ (possible Fe will be eluted simultaneously with $\mathrm{U}$ ).

\section{Uranium source preparation}

The uranium source can be prepared by fluoride co-precipitation as follows:

- To the eluted solution (about $20 \mathrm{~mL}$ of $1 \mathrm{M} \mathrm{HCl}$ ), add $50 \mu \mathrm{L}$ of $\mathrm{Nd}^{3+}$ solution and an amount of $\mathrm{TiCl}_{3}$ (15\% solution) drop by drop to change the colour of solution to purple, then add excess $1 \mathrm{~mL}$, (the colour of $\mathrm{Fe}^{3+}$ disappears; iron is reduced). The excess $\mathrm{TiCl}_{3}$ is to keep the purple colour in solution (means uranium is kept in the tetravalent state). If the purple colour disappears, add other drops to obtain the purple colour again.

- Add $5 \mathrm{~mL}$ of $40 \%$ HF solution to the sample and leave for about $30 \mathrm{~min}$ and filter on $0.1 \mu \mathrm{m}$ polypropylene membrane filter and polysulfone filter funnel $25 \mathrm{~mm} / 50 \mathrm{~mL}$.

- Wash the precipitate with $3 \mathrm{~mL}$ of $4 \% \mathrm{HF}$ solution, and then with $3 \mathrm{~mL}$ of $80 \%$ ethanol.

- Dry the sample at $50^{\circ} \mathrm{C}$ for $10 \mathrm{~min}$ and mount on a stainless-steel disc (diameter is $27 \mathrm{~mm}$ ) with very small amount of all-purpose, fast drying glue for measurement by $\alpha$-spectrometry. 
The sample is now ready to be measured on the alpha spectrometer

\section{Determination of thorium $\alpha$-emitters}

Dry prescribed amount of the soil, for approximately $3 \mathrm{~h}$, at $105^{\circ} \mathrm{C}$. Grind and sieve the soil (100 mesh), then ash in silica dish for about $20 \mathrm{~h}$, at $550^{\circ} \mathrm{C}$. Calculate the weight equivalent to $1 \mathrm{~g}$ of dry soil. In 250-mL Teflon beaker, spike an appropriate weight of the sample ash with $500 \mu \mathrm{L}$ of ${ }^{229} \mathrm{Th}(10-15 \mathrm{dpm} / \mathrm{ml})$ and digest with $\mathrm{HNO}_{3}-\mathrm{HClO}_{4}$ - $\mathrm{HF}$ mixture to dissolve. Evaporate to near dryness, and then dissolve the salt in concentrated $\mathrm{HNO}_{3}$. Add concentrated $\mathrm{HNO}_{3}$ acid to obtain $20 \mathrm{~mL}$ of $8 \mathrm{M}$ acid solution.

\section{Anion exchange separation of Th}

- Pack a small column (10 mL bed volume) with the anion exchange resin (AG 1-X8) by adding its slurry in distilled water to the column filled with distilled water to occupy $5 \mathrm{~mL}$ as a bed volume.

- Condition the column by passing $20 \mathrm{~mL}$ of $8 \mathrm{M} \mathrm{HNO}_{3}$, to change the form of the resin from the $\mathrm{Cl}^{-}$form to the $\mathrm{NO}_{3}^{-}$form, and discard the effluent.

- Load the sample solution to the column and then wash the resin with excess $20 \mathrm{~L}$ of $8 \mathrm{M} \mathrm{HNO}_{3}$. Discard effluents.
- In a clean beaker elute thorium from the column by passing $20 \mathrm{~mL}$ of $1 \mathrm{M} \mathrm{HNO}_{3}$.

\section{Thorium source preparation}

The thorium source can be prepared by fluoride coprecipitation as follows:

- To the Th solution that eluted from the column, add $100 \mu \mathrm{L}$ of $70 \% \mathrm{NaHSO}_{4}$ and evaporate to dryness, then add $3 \mathrm{~mL}$ concentrated $\mathrm{HNO}_{3}$ and evaporate again.

- Repeat addition of $\mathrm{HNO}_{3}$ and evaporation twice to destroy and evaporate any organic materials that may be eluted from the resin.

- Add about $2 \mathrm{~mL}$ of $1 \mathrm{M} \mathrm{HNO}_{3}$ to dissolve the solid material, and then warm to insure complete dissolution. Filter (if necessary) through ordinary slow or medium filter paper.

- Wash the beaker and the filter paper with $1 \mathrm{M}$ $\mathrm{HNO}_{3}$ and dilute the sample with $1 \mathrm{M} \mathrm{HNO}_{3}$ to about $20 \mathrm{~mL}$.

- Add $50 \mu \mathrm{L}$ of $\mathrm{Nd}^{3+}$ solution, then $5 \mathrm{~mL}$ of $40 \%$ $\mathrm{HF}$ and leave to stand for $1 \mathrm{~h}$ for precipitate development.

- Filter on $0.1 \mu \mathrm{m}$ polyethylene membrane filter, using polysulfone filter funnel $25 \mathrm{~mm} / 50 \mathrm{~mL}$. Wash the precipitate with $3 \mathrm{~mL}$ of $4 \% \mathrm{HF}$ solution, and then with $3 \mathrm{~mL}$ of $80 \%$ ethanol.

- Mount the thorium source on the stainless-steel disc for $\alpha$-particle counting as in case of $U$. 